\title{
'|||||||||||||||||||||||||||||||||||||||||||||||||||||||||||||||||.
}

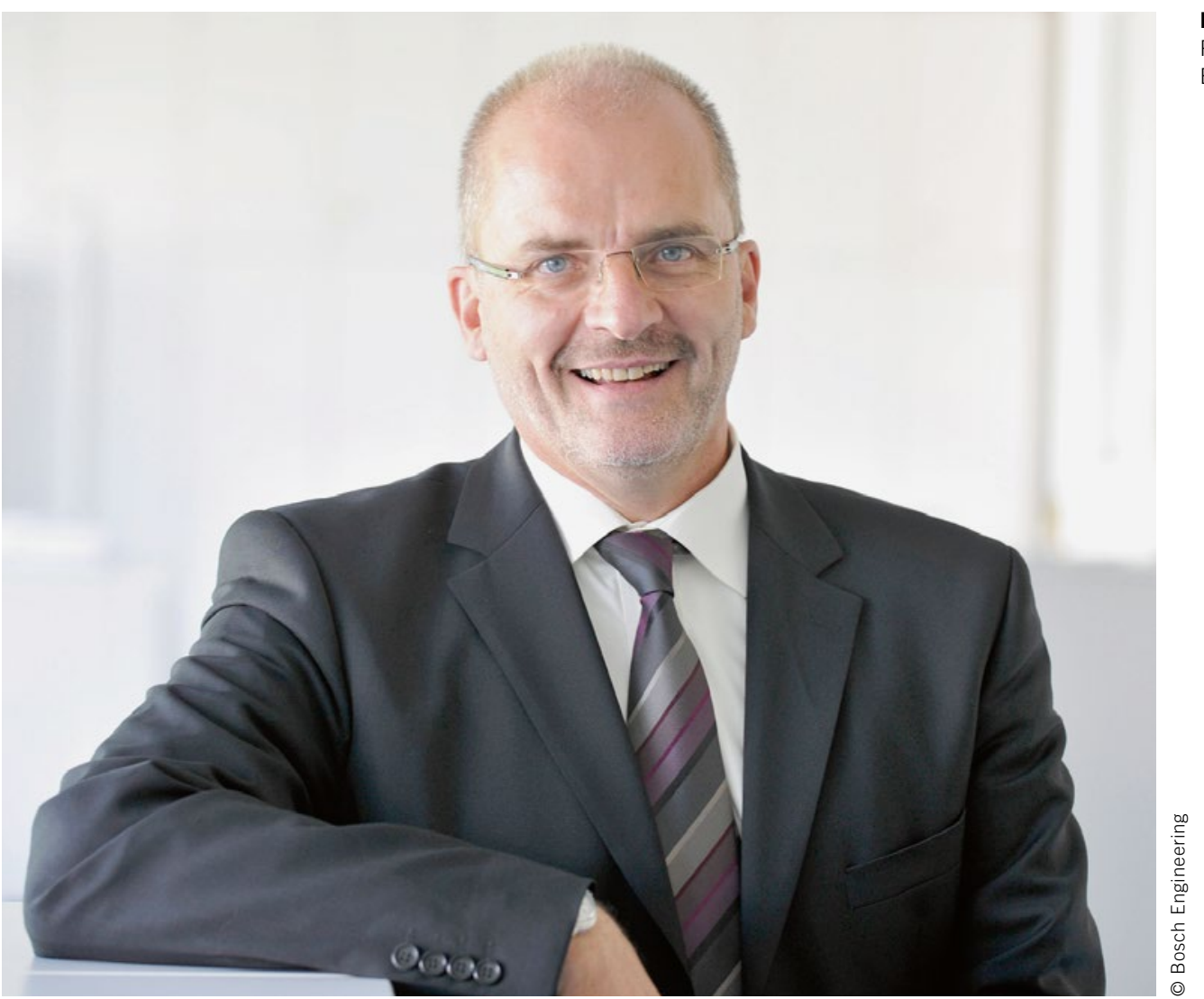

Bernhard Bihr

President of Bosch

Engineering $\mathrm{GmbH}$

\section{Important Pillar for their Careers}

This year saw 15 racing teams enter the new "Driverless" category for the first time, underlining the relevance and professionalism of the Formula Student Germany (FSG) approach. For us, this also reaffirms our wish to support many young, committed engineers. There is no better springboard than FSG as future university graduates look to start their careers with a bang. No other project allows students to work in such a practice-oriented manner and acquire such comprehensive knowledge, because, besides fundamental technical knowledge, a certain curiosity for getting to grips with new activity areas is crucial. Ultimately, it is not the fastest car, but the team with the best overall package of design, racing performance, financial planning and sales arguments that wins. This demands various skills - and that is precisely what we at Bosch Engineering seek. Diversity and/or strategic alignment is one of our core values. We bring individual competences, experience and working style together to help us innovate and to consolidate our global success. We have been providing direct support to FSG, the main organiser of the event, since 2007, as well as to selected teams each season. My mission, more than anything else, is to help spark enthusiasm for tech- nology among students and promote young, highly motivated and interested engineers. Our developers support the racing teams we sponsor, for example, with various technical workshops. A major highlight is undoubtedly the annual preparatory workshop at our Boxberg test track, where teams can train their drivers and fine-tune their racing cars. They also have the opportunity to collaborate and exchange ideas with other teams and our experienced engineers. Many of the latter are ex FSG team-members since their student days and thus best-placed to give tips and advice.

FSG offers an unrivalled opportunity to engage many qualified students in dialogue. Recent years have seen us recruit more than 180 students and graduates with an FSG background. Despite the additional pressure, I would encourage all interested students to get involved with one of the numerous teams. In my opinion, the effort pays off twofold: as well as consolidating their technical knowledge through practical experience, young engineers can also establish valuable contacts for their network and practice interdisciplinary teamwork through close collaboration with suppliers and car manufacturers. 